\title{
DANOS E NÍVEL DE DANO ECONÔMICO DO PERCEVEJO BARRIGA VERDE NA CULTURA DO MILHO
}

\author{
MARCELA MARCELINO DUARTE ${ }^{1}$ CRÉBIO JOSÉ ÁVILA² e VIVIANE SANTOS²
}

${ }^{I}$ Raza Fuerte SRL, Santa Cruz de La Sierra, Santa Cruz, Bolivia-marcela@rafazuerte.com.br

${ }^{2}$ EmbrapaAgropecuária Oeste,Dourados, MS,Brasil-crebio.avila@embrapa.br,vivisantos@usp.br

Revista Brasileira de Milho e Sorgo, v.14, n.3, p. 291-299, 2015

\begin{abstract}
RESUMO - O comportamento produtivo do milho na presença de diferentes níveis populacionais de insetos adultos do percevejo Dichelops melacanthus em diferentes estádios de desenvolvimento da planta foi determinado em casa de vegetação e no campo com o objetivo de estimar o seu nível de dano econômico (NDE). A massa seca da parte aérea e o rendimento de grãos foram significativamente reduzidos na presença do percevejo, independente dos estádios de desenvolvimento da planta (V1 a V3). Em campo, utilizando-se gaiolas e infestando as plantas no estádio V1 durante 10 dias consecutivos, não foram observadas diferenças no peso de 100 grãos em relação às densidades populacionais utilizadas. No entanto, houve redução significativa no rendimento de grãos com o aumento da densidade populacional do percevejo. Em função dos resultados obtidos, é possível estimar que o NDE para $D$. melacanthus na cultura do milho é de 0,8 percevejo $/ \mathrm{m}^{2}$, densidade populacional na qual o controle da praga é justificado economicamente.
\end{abstract}

Palavras - chave: Dichelops melacanthus, estádio de desenvolvimento da planta, rendimento de grãos, densidade populacional, injúria.

\section{DAMAGE AND ECONOMIC THRESHOLD OF THE STINK BUG ON CORN CROP}

\begin{abstract}
This work aimed to evaluate the effect of the population level and infestation time of D. melacanthus in corn, as well as to estimate its economic threshold level (ET). The damage experiment was carried out under greenhouse. Corn plants were infested with 4 adult bugs on five different plant stages for a period of 10 days. Shoot dry mass content was significantly reduced by the presence of the stinkbug at all stages and grain yield was affected by the stinkbug when infestations occurred in the stages V1, V2 and V3. In the economic damage threshold level experiment, corn plants at one leaf stage were submitted to different infestation levels of stink bug for a period of 10 days, inside cages in the field. The weight of 100 grains was not significantly affected by populations of the stink bug; however, grain yield was significantly reduced when the population density of the bug in cages increased. The economic threshold level of the D. melacanthus for corn was $0.8 \mathrm{stink} \mathrm{bug} / \mathrm{m}^{2}$.
\end{abstract}

Key words: Dichelops melacanthus, plant stage of the development, yield, population density, injury. 
O Brasil é o terceiro maior produtor mundial de milho, depois dos Estados Unidos e da China, com uma produção anual de quase 80.000.000 toneladas (Agrianual, 2015). Fatores como intensificação do cultivo, especialmente na segunda época ("safrinha”), rotação e sucessão de cultivos em uma mesma área têm modificado os agroecossistemas e o manejo fitossanitário do milho, proporcionando alterações na composição e abundância das espécies de insetos que nela ocorrem (Waquil et al., 2004). No Brasil, o cultivo do milho safrinha superou em produção a primeira safra (verão) com 44.000 .000 e 28.800 .000 toneladas, respectivamente, na safra 2014/ 2015 (Agrianual, 2015).

$\mathrm{O}$ plantio direto propiciou vários benefícios à agricultura, como por exemplo permitir o gerenciamento de grandes áreas, já que não é necessário o preparo do solo; consequentemente, há redução significativa no volume de trabalho e maquinários, além de ser uma forma eficaz no combate à erosão e na manutenção de água e de fertilizantes no solo (Triplett \& Dick, 2008). Contudo, este sistema de cultivo tem favorecido o desenvolvimento e a sobrevivência de algumas pragas por fornecer abrigo para algumas espécies, como é o caso dos percevejos fitófagos que podem causar expressivos prejuízos na cultura, caso não sejam devidamente controlados (Chocorosqui \& Panizzi, 2004).

Os percevejos fitófagos (Hemiptera: Pentatomidae) são insetos sugadores que apresentam como principal característica o hábito de introduzir seus estiletes no substrato de alimentação, atingindo várias estruturas das plantas, embora as sementes e os frutos sejam os locais preferenciais para sua alimentação, especialmente no caso da soja (Panizzi, 2000). Nas últimas décadas, algumas espécies do gênero Dichelops, que no passado eram consideradas pragas secundárias da soja, passaram a atacar principalmente os cultivos de milho e de trigo, especialmente quando as plantas estão no início de desenvolvimento vegetativo (Ávila \& Panizzi, 1995; Gomes, 1998; Chocorosqui \& Panizzi, 2004; Rosa-Gomes, 2011). Por exemplo, as espécies Dichelops melacanthus (Dallas, 1851) (Hemiptera: Pentatomidae) e D. furcatus (Fabricius, 1775) (Hemiptera: Pentatomidae) estão entre aquelas com potencial para causar danos no milho quando se alimentam no seu meristema apical; ao extrair a seiva das plantas, injetam substâncias que têm ação tóxica para as mesmas (Brustolin et al., 2011).

Particularmente na região Centro-Oeste, onde o milho safrinha é cultivado após a colheita da soja, D. melacanthus encontra condições de clima de diversidade alimentar que favorece a sobrevivência e a multiplicação do inseto a ponto de atingir populações que podem causar danos significativos na cultura, especialmente nos seus estádios iniciais de desenvolvimento (Ávila \& Panizzi, 1995).

A tecnologia do milho geneticamente modificado (Bt), apesar de ser uma importante ferramenta para o controle de lagartas e de ser amplamente cultivado no Brasil atualmente, não apresenta efeito sobre os insetos da ordem Hemiptera, à qual pertencem os percevejos. Para estes insetos, é imprescindível a intervenção por um outro método de controle quando a sua população atinge níveis elevados no campo (Cruz et al., 2012).

Embora já existam alguns estudos que mostram alternativas para o controle de D. melacanthus na cultura do milho (Albuquerque et al., 2006; Martins et al., 2009; Brustolin et al., 2011), a relação entre os danos e a presença do inseto nas plantas de milho, bem como o seu NDE, ainda não foram efetivamente determinados no Brasil. Essas informações fornecerão subsídios para o manejo integrado desta praga na cultura, orientando sobre o momento ideal da utilização de medidas de controle. 
O objetivo desta pesquisa foi avaliar a resposta do milho na presença do percevejo D. melacanthus em diferentes estádios de desenvolvimento da planta, bem como avaliar o efeito de diferentes níveis populacionais desta praga na cultura, visando a estimar o nível de dano econômico.

\section{Material e Métodos}

Foram conduzidos dois experimentos para avaliar a capacidade de $D$. melacanthus causar danos em milho. O primeiro foi realizado em casa de vegetação, utilizando-se a cultivar Exceller semeada em vasos com capacidade para 13 litros, conduzindo-se duas plantas de milho por vaso. As plantas de cada vaso foram infestadas com quatro insetos adultos do percevejo barriga verde em cinco diferentes estádios de desenvolvimento: V1 (1 folha); V2 (2 folhas); V3 (3 folhas); V4 (4 folhas); e V5 (5 folhas). Sobre as plantas de cada vaso, foi colocada uma armação de ferro revestida com tecido do tipo filó para contenção dos insetos durante o período de infestação, que foi de dez dias. Os vasos foram vistoriados diariamente para a reposição de eventuais insetos mortos no interior das gaiolas. Os percevejos adultos utilizados no experimento foram coletados em lavouras de milho da região de Dourados, MS e mantidos em uma gaiola contendo plantas de milho até a época de instalação do ensaio. $\mathrm{O}$ delineamento experimental foi o inteiramente casualizado com seis tratamentos (cinco estádios com infestação e uma testemunha sem insetos) em sete repetições (vasos com duas plantas). As plantas de milho foram conduzidas até a colheita para a determinação da massa seca da parte aérea e o rendimento de grãos. Os dados obtidos foram submetidos a análise de variância e as médias dos tratamentos foram comparadas pelo teste de Tukey ao nível de 5\% de probabilidade.
O segundo experimento foi conduzido em campo na cidade de Dourados, MS (S $22^{\circ} 14^{\prime}$, W 54 49', $408 \mathrm{~m}$ ) no mês de fevereiro em Latossolo Vermelho, distroférrico, argiloso seguindo as recomendações técnicas de adubação na base para a cultura (Fancelli $\&$ Dourado Neto, 2000). A unidade experimental consistiu de uma gaiola em armação de ferro com dimensões de 1,0 $\mathrm{m}$ de comprimento por 0,90 $\mathrm{m}$ de largura e $0,90 \mathrm{~m}$ de altura, revestida com tela de nylon que abrangia cinco plantas de milho, perfazendo-se uma área útil da parcela de $0,90 \mathrm{~m}^{2}$. No estádio V1 (uma folha), as plantas foram infestadas com diferentes níveis populacionais de adultos de D. melacanthus $(0$, 2, 4, 6 e 8 percevejos/gaiola) por um período de 10 dias. As gaiolas foram vistoriadas diariamente para reposição de eventuais insetos mortos. Os percevejos utilizados no experimento foram coletados em lavouras comerciais da região e mantidos em gaiola contendo plantas de milho até o momento da instalação do ensaio. O experimento foi conduzido no delineamento de blocos casualizados com cinco tratamentos (níveis de infestação do percevejo) e cinco repetições (gaiolas). Após o período de infestação, os percevejos e as gaiolas foram retirados das unidades experimentais e as plantas pulverizadas periodicamente com o inseticida clorpirifós (480 g.ha-1 $)$ até a fase de maturação dos grãos para eliminar possíveis infestações das plantas por outras pragas. O ensaio foi conduzido até a colheita para determinação do peso das espigas e o rendimento de grãos em cada parcela. Os resultados de produtividade foram submetidos a análise de regressão ao nível de 5\% de significância. Para o cálculo do nível de dano econômico (NDE), utilizou-se a fórmula sugerida por Nakano et al. (1981), como segue: $\% \mathrm{D}=100 \times \mathrm{Ct} / \mathrm{V}$, sendo $\mathbf{C t}$ o custo de controle e $\mathbf{V}$ o valor da cultura. Considerou-se o custo de controle do percevejo na cultura do milho correspon- 
dente a $\mathrm{R} \$ 102,92$ por hectare (cento e dois reais e noventa e dois centavos), equivalente a aplicação dos inseticidas imidacloprido + tiodicarbe $(45,0+135,0$ $\mathrm{g} \mathrm{ha}^{-1}$ ) nas sementes e uma pulverização com os inseticidas imidacloprido + betaciflutrina $(75,0+9,4$ $\mathrm{g} \mathrm{ha}^{-1}$ ) sobre as plantas, além do custo da aplicação tratorizada do inseticida na cultura.

\section{Resultados e Discussão}

O peso seco da parte aérea das plantas foi reduzido na presença do percevejo barriga verde em todos os estádios de desenvolvimento em que o milho foi infestado com esta praga (Tabela 1). Todavia, este efeito deletério foi mais acentuado em plantas infestadas no estádio V1 (apenas uma folha). Os resultados evidenciam que a injúria causada pelo percevejo no milho afetou o acúmulo de matéria seca pela planta, o que, consequentemente, afetou o seu desenvolvimento. Estes resultados diferem dos obtidos por Roza-Gomes et al. (2011), que encontraram valores de massa seca da parte aérea de plantas de milho similares para plantas infestadas e não infestadas com esta praga. No entanto, esses mesmos autores observaram redução na altura das plantas infestadas, redução do número de folhas expandidas, aumento da intensidade de injúria e redução da massa seca das raízes do milho.

$\mathrm{O}$ inseto reduziu também o rendimento de grãos do milho para as infestações realizadas nas plantas com os estádios V1, V2 e V3 quando comparado às plantas não infestadas $(p \leq 0,05)$ (Tabela 1). Já nas plantas infestadas nos estádios V4 e V5, não foram constatadas reduções em relação ao rendimento de grãos obtidos nas plantas sem infestação. Resultados similares foram observados por Bianco $(2004,2005)$, o qual constatou que as plantas de milho infestadas no início de seu desenvolvimento (até nove dias após a emergência) foram mais suscetíveis ao ataque do percevejo barriga verde em comparação às plantas mais desenvolvidas (16 DAE). Vários outros autores também argumentam que o dano do percevejo barriga verde em plantas de milho com até 25 dias após emergência é maior do que em plantas mais desenvolvidas, podendo ocorrer até a morte da planta quando acontece um ataque acentuado no início do desenvolvimento das mesmas (Ávila \& Panizzi, 1995; Cruz et al., 1999; Viana et al., 2001; Gomez \& Ávila, 2001; Viana et al., 2001; Link, 2006).

TABELA 1. Peso da massa seca da parte aérea e rendimento médio de grãos de milho (média \pm erro padrão) obtidos de plantas infestadas em diferentes estádios de desenvolvimento com adultos de D. melacanthus. Dourados, MS.

\begin{tabular}{ccc}
\hline $\begin{array}{c}\text { Estádios de } \\
\text { desenvolvimento da planta }\end{array}$ & $\begin{array}{c}\text { Massa seca da parte aérea } \\
(\mathrm{g} / \text { vaso })^{1}\end{array}$ & $\begin{array}{c}\text { Rendimento de grãos } \\
(\mathrm{g} / \mathrm{vaso})^{1}\end{array}$ \\
\hline Testemunha & $270,20 \pm 11,60 \mathrm{a}$ & $45,13 \pm 4,16 \mathrm{a}$ \\
1 folha (V1) & $58,20 \pm 24,10 \mathrm{c}$ & $3,36 \pm 2,17 \mathrm{~b}$ \\
2 folhas (V2) & $81,70 \pm 26,85 \mathrm{bc}$ & $8,64 \pm 5,54 \mathrm{~b}$ \\
3 folhas (V3) & $102,70 \pm 17,03 \mathrm{bc}$ & $11,47 \pm 3,22 \mathrm{~b}$ \\
4 folhas (V4) & $140,40 \pm 9,55 \mathrm{~b}$ & $18,32 \pm 9,67 \mathrm{ab}$ \\
5 folhas (V5) & $131,80 \pm 12,31 \mathrm{bc}$ & $15,56 \pm 7,39 \mathrm{ab}$ \\
\hline
\end{tabular}

${ }^{1}$ Médias seguidas da mesma letra na coluna não diferem estatisticamente pelo teste de Tukey $(p \leq 0,05)$. 
Segundo Vieira Jr. (1999), todas as folhas e espigas que a planta de milho eventualmente irá produzir são definidas até o estádio V3. Pode-se dizer, com base nisso, que o número máximo de grãos ou a produção potencial do milho é definido(a) nos estádios iniciais de desenvolvimento da planta. Dessa forma, o ataque do percevejo nestes estádios de desenvolvimento pode ter interferido negativamente no desenvolvimento fisiológico das plantas e, consequentemente, afetado o seu potencial produtivo. Os resultados desta pesquisa reforçam o alto potencial que o percevejo $D$. melacanthus tem de causar danos na cultura do milho. Copatti \& Oliveira (2011) avaliaram as injúrias foliares causadas pelo percevejo barriga verde e pelo percevejo marrom Euschistus heros (Fabricius) (Hemiptera: Pentatomidae) no milho e concluíram que os danos causados por D. melacanthus foram superiores aos observados por E. heros, independente da densidade de percevejos estudada ( 1,2 ou 3/ planta) e independente do período de infestação $(0,7,14,21$ dias). Os autores também relataram a presença de folhas centrais retorcidas ("encharutamento") e de orifícios de alimentação nas plantas com a infestação de três percevejos de D. melacanthus / planta.

Não houve correlação entre o peso médio de 100 grãos do milho e a densidade do percevejo. Observou-se, no entanto, uma relação negativa entre o peso médio das espigas e as densidades populacionais de D. melacanthus $(p \leq 0,05)$, embora o coeficiente de determinação encontrado fosse relativamente baixo (Figura 1). Contudo, o rendimento de grãos apresentou relação negativa com o incremento dos níveis de infestação do percevejo (Figura 2) $\left(\mathrm{R}^{2}=0,92 ; p\right.$ $\leq 0,05$ ), evidenciando que o aumento da densidade populacional do inseto reduz o rendimento de grãos da cultura.
Na fase de enchimento de grãos, inicia-se a transformação dos açúcares em amido, contribuindo para o incremento de peso seco dos mesmos. Tal incremento ocorre devido à translocação dos fotoassimilados presentes nas folhas e no colmo para as espigas e os grãos que estão em formação (Magalhães \& Jones, 1990; Magalhães et al., 1998). Pode-se inferir que a produtividade do milho (peso das espigas) foi provavelmente afetada pelo ataque do percevejo nos estádios iniciais de desenvolvimento da planta, condição esta que afetou negativamente o desenvolvimento e a formação dos grãos nas espigas.

Através dos valores de produção de milho obtidos nas parcelas com as diferentes densidades populacionais do percevejo no intervalo de dois a oito insetos por $\mathrm{m}^{2}$, foi possível estimar o rendimento de grãos por hectare que, ao ser comparado com a testemunha (plantas não infestadas), possibilitou obter o percentual de perdas para cada densidade populacional utilizada. A equação que relacionou as densidades populacionais do percevejo e os rendimentos de grãos apontou redução de 5,98\% na produção para cada percevejo acrescentado na gaiola. Transformando os dados das perdas, estimou-se que um percevejo por $\mathrm{m}^{2}$ causaria uma redução de, aproximadamente, 5,38\% na produção de grãos de milho / hectare.

Utilizando-se a fórmula sugerida por Nakano et al. (1981), determinou-se o percentual de dano (\% D) no milho que equivale ao nível de dano econômico (4,27\%). Conhecido esse percentual de dano, estabeleceu-se uma regra de três simples entre o percentual de dano causado pelas diferentes densidades populacionais do percevejo / gaiola e o percentual de dano obtido com a fórmula previamente citada. Dessa maneira, verificou-se que o número de percevejos que causa dano equivalente ao custo do seu controle ( $\mathrm{R} \$$ 102,92) representa o nível de dano econômico da pra- 


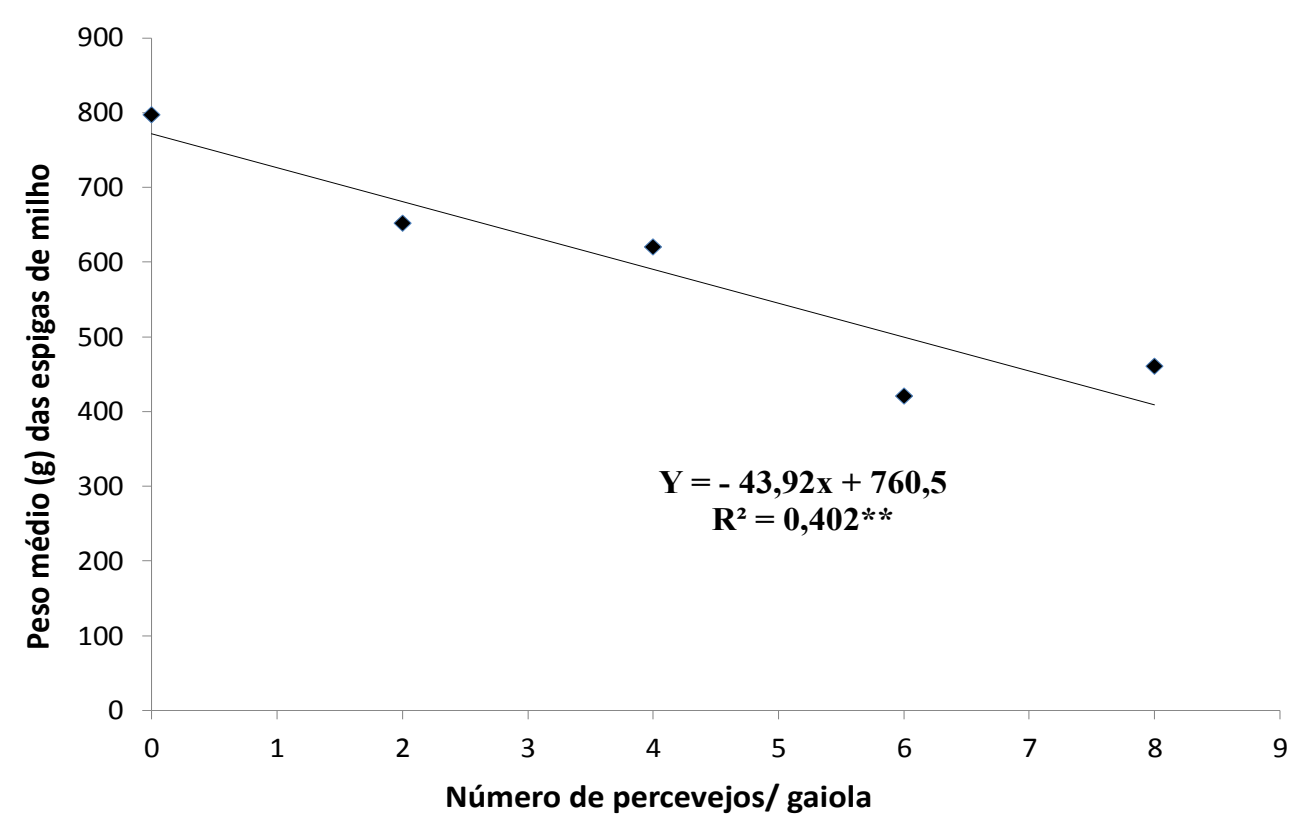

FIGURA 1. Peso médio de espigas de milho obtido de plantas infestadas com diferentes densidades populacionais de adultos de D. melacanthus. Dourados, MS.

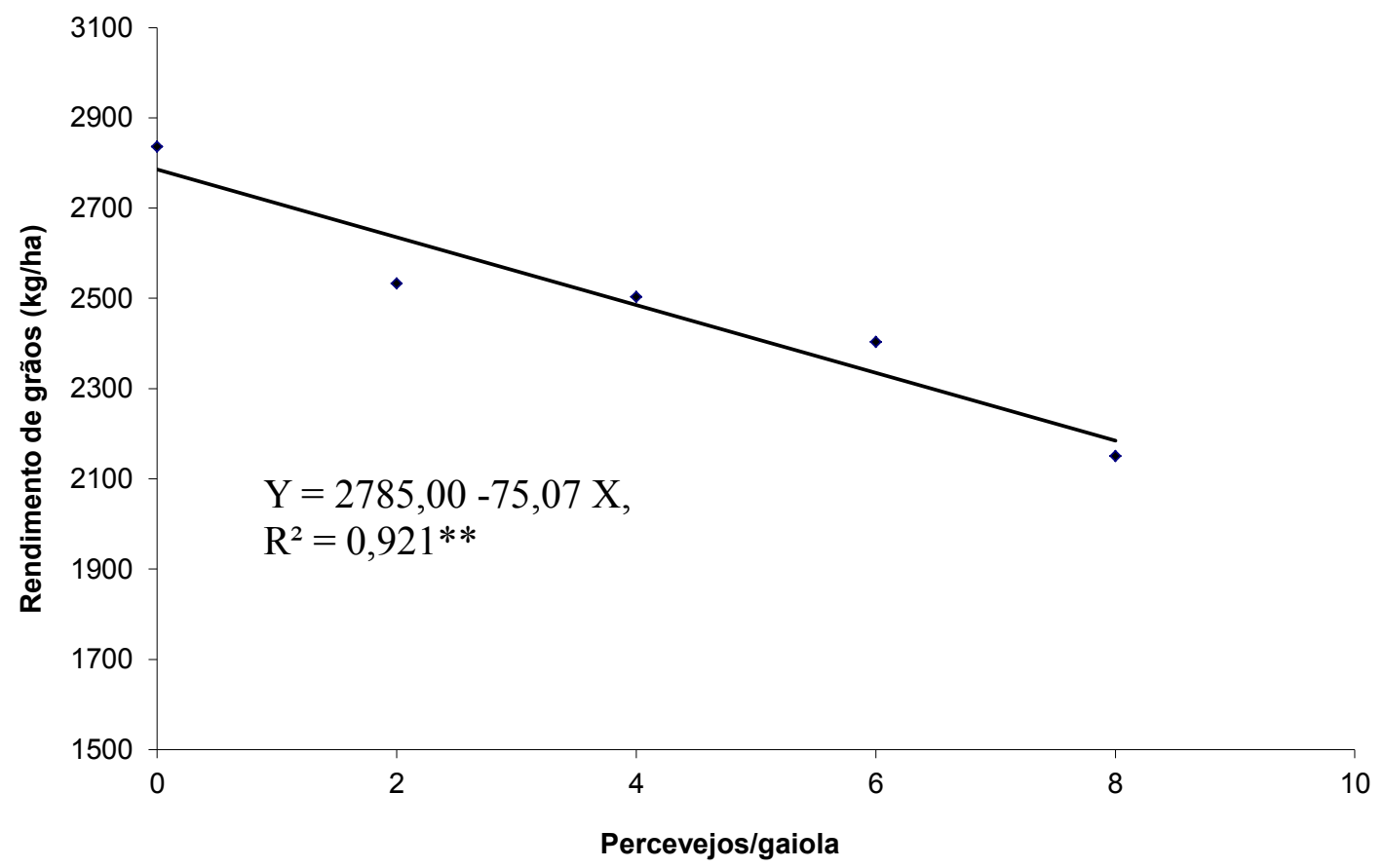

FIGURA 2. Relação entre o rendimento de grãos de milho $\left(\mathrm{Kg} \mathrm{ha}^{-1}\right)$ e a densidade populacional de adultos do percevejo barriga verde, D. melacanthus. Dourados, MS. 
ga para a cultura do milho, que foi de 0,8 percevejo por $\mathrm{m}^{2}$, considerando o rendimento médio de grãos na área de estudo (6.568 $\left.\mathrm{kg} \mathrm{ha}^{-1}\right)$.

Gassen (1994, 1996) e Cruz et al. (1999) recomendam medidas de controle para o percevejo barriga verde na cultura do milho quando forem encontrados dois percevejos $/ \mathrm{m}^{2}$, nível esse superior ao NDE encontrado nesta pesquisa $\left(0,8\right.$ percevejo $\left./ \mathrm{m}^{2}\right)$, considerando-se a necessidade de uma aplicação de inseticida nas sementes e uma pulverização após a emergência da cultura. Esses resultados diferem também do citado por Bianco (2004), que encontrou o NDE de dois percevejos para cada cinco plantas de milho, embora este autor tenha trabalhado com cultivares e condições diferentes das utilizadas neste estudo.

Os resultados evidenciaram o elevado potencial de dano que o percevejo barriga verde apresenta para a cultura do milho, sendo o NDE inferior a um percevejo por $\mathrm{m}^{2}$. Naturalmente, o NDE pode variar de ano para ano, dependendo do estádio de desenvolvimento da planta em que ocorre a infestação do percevejo, do nível de produtividade da cultura, do grau de suscetibilidade da cultivar, bem como do custo de controle da praga na cultura. As informações obtidas nesta pesquisa servirão para a orientação na tomada de decisão visando a implementação de táticas de controle do percevejo barriga verde, D. Melacanthus, na cultura de milho.

\section{Conclusões}

O percevejo barriga verde causa significativos danos em milho, especialmente quando a infestação ocorre nos estádios iniciais de desenvolvimento da planta (V1 a V3), repercutindo negativamente no potencial produtivo da cultura.
O nível de dano econômico do percevejo barriga verde para a cultura do milho é de 0,8 percevejo por $\mathrm{m}^{2}$ quando esta praga for constatada no estádio de desenvolvimento de uma folha (V1).

\section{Agradecimentos}

À Fundação de Apoio ao Desenvolvimento de Ensino, Ciência e Tecnologia do Estado de Mato Grosso do Sul (Fundect), pelo financeamento do trabalho e pela bolsa de estudos concedida à primeira e à última autoras.

\section{Referências}

AGRIANUAL. Anuário da Agricultura Brasileira. Milho. São Paulo: Instituto FNP, 2015. Disponível em: <http://agrianual.com.br/secao/ culturas/milho $>$. Acesso em: 23 ago. 2015.

ALBUQUERQUE, F. A.; BORGES, L. M.; IACONO, T. O.; CRUBELATI, N. C. S.; SINGER, A. C. Eficiência de inseticidas aplicados em tratamento de sementes e em pulverização, no controle de pragas iniciais do milho. Revista Brasileira de Milho e Sorgo, Sete Lagoas, v. 5, n. 1, p. 15-25, 2006.

ÁVILA, C. J.; PANIZZI, A. R. Ocurrence and damage by Dichelops (Neodichelops) melacanthus (Dallas) (Heteroptera: Pentatomidae) on corn. Anais da Sociedade Entomológica do Brasil, Piracicaba, v. 24, n. 1, p. 193-194, 1995.

BIANCO, R. Manejo de pragas do milho em plantio direto. In: REUNIÃO ITINERANTE DE FITOSSANIDADE DO INSTITUTO BIOLÓGICO-GRÃOS, 11.; ENCONTRO DE FITOSSANIDADE DE PLANTIO DIRETO NA PALHA DO CLUBE AMIGOS DA TERRA 
DE AGUAÍ, 1., 2005, Aguaí. Anais... Aguaí: Instituto Biológico, 2005. p. 8-17.

BIANCO, R. Nível de dano e período crítico do milho ao ataque do percevejo barriga verde (Dichelops melacanthus). In: CONGRESSO NACIONAL DE MILHO E SORGO, 25.; SIMPÓSIO BRASILEIRO SOBRE A LAGARTA DO CARTUCHO Spodoptera frugiperda, 1., 2004, Cuiabá. Resumos... Sete Lagoas: ABMS: Embrapa Milho e Sorgo: Empaer, 2004. p. 172. BRUSTOLIN, C.; BIANCO, R.; NEVES, P. M. O. J. Inseticidas em pré e pós-emergência do milho (Zea mays L.) associados ao tratamento de sementes sobre Dichelops melacanthus (Dallas) (Hemiptera: Pentatomidae). Revista Brasileira de Milho e Sorgo, Sete Lagoas, v. 10, n. 3, p. 215-223, 2011.

CHOCOROSQUI, V. R.; PANIZZI, A. R. Impact of cultivation systems on Dichelops melacanthus (Dallas) (Heteroptera: Pentatomidae) population and damage and its chemical control on wheat. Neotropical Entomology, Londrina, v. 33, n. 4, p. 487-492, 2004.

COPATTI, J. F.; OLIVEIRA, N. C. Danos iniciais causados pelos percevejos Dichelops melacanthus e Euschistus heros (Hemiptera: Pentatomidae) em plantas de milho. Campo Digit@1, Campo Mourão, v. 6, n. 1,p. 54-60,2011. CRUZ, I.; MENDES, S. M.; VIANA, P. A. Importância econômica e manejo de insetos sugadores associados à parte aérea de plantas de milho Bt. Sete Lagoas: Embrapa- CNPMS, 2012. 14 p. (Embrapa-CNPMS. Circular técnica, 175). CRUZ, I.; VIANA, P. A.; WAQUIL, J. M. Manejo das pragas iniciais de milho mediante tratamento de sementes com inseticidas sistêmicos. Sete Lagoas: Embrapa-CNPMS, 1999. 39 p.
(Embrapa-CNPMS. Circular técnica, 31).

FANCELLI, A. L.; DOURADO NETO, D. Produção

de milho. Guaíba: Agropecuária, 2000. 360 p.

GASSEN, D. N. Manejo de pragas associadas à cultura do milho. Passo Fundo: Aldeia Norte, 1996. $127 \mathrm{p}$.

GASSEN, D. N. Pragas associadas à cultura do milho. Passo Fundo: Aldeia Norte, 1994. 92 p.

GOMEZ, S. A. Controle químico do percevejo Dichelops (Neodichelops melacanthus) (Dallas) (Heteroptera: Pentatomidae) na cultura do milhosafrinha.Dourados:Embrapa-CPAO,1998.

5 p. (Embrapa-CPAO. Comunicado técnico, 44). GOMEZ, S. A.; ÁVILA C. J. Milho: barriga-verde na safrinha. Cultivar: grandes culturas, Pelotas, v. 3, n. 26, p. 28-29, 2001.

LINK, D. Praga na emergência. Cultivar: grandes culturas, Pelotas, v. 88, n. 8, p. 32-33, 2006.

MAGAlHÃES, P. C.; DURÃES, F. O. M.; OLIVEIRA, A. C. Efeitos do quebramento do colmo no rendimento de grãos de milho. Ciência e Agrotecnologia, Lavras, v. 22, n. 3, p. 279-289, 1998.

MAGALHÃES, P. C.; JONES, R. Aumento de fotoassimilados na taxa de crescimento e peso final dos grãos de milho. Pesquisa Agropecuária Brasileira,Brasília,v.25,n.12,p. 1747-1754,1990. MARTINS, G. L. M.; TOSCANO, L. C.; TOMQUELSKI， G. V.; MARUYAMA，W. I. Controle químico do percevejo barrigaverde Dichelops melacanthus (Hemiptera: Pentatomidae) na cultura do milho. Arquivos do Instituto Biológico, São Paulo, v. 76, n. 3, p. 475-478, 2009.

NAKANO, O.; SILVEIRA NETO, S.; ZUCCHI, R. A. Entomologia econômica. São Paulo: Livroceres; Piracicaba: ESALQ, 1981. 314 p. 
PANIZZI, A. R. Suboptimal nutrition and feeding behavior of Hemipterans on less preferred plant food sources. Anais da Sociedade Entomológica do Brasil, Londrina, v. 29, n. 1, p. 1-12, 2000. ROZA-GOMES, M. F.; SALVADORI, J. R.; PEREIRA, P. R. V. S.; PANIZZI, A. R. Injúrias de quatro espécies de percevejos pentatomídeos em plântulas de milho. Ciência Rural, Santa Maria, v. 41, n. 7, p. 1-5, 2011.

TRIPLETT, G. B.; DICK, W. A. No-tillage crop production:arevolutioninagriculture.Agronomy Journal, Madison, v. 100, n. 3, p. 153-165, 2008. VIANA, P. A.; CRUZ, I.; OLIVEIRA, L. J.; CORREA-FERREIRA, B. S. Manejo de pragas em agroecossistemas sob plantio direto. Informe Agropecuário, Belo Horizonte, v. 22, n. 208, p. 63-72, 2001.

VIEIRA JÚNIOR, P. A. Milho. In: CASTRO, P. R. C.; KLUGE, R. A. (Coord.). Ecofisiologia de cultivos anuais: trigo, milho, soja, arroz e mandioca. São Paulo: Nobel, 1999.

WAQUIL, J. M.; ÁVILA, C. J.; VIANA, P. A.; VALICENTE, F. H.; CRUZ, I. Ocorrência e controle de pragas na cultura do milho no Mato Grosso do Sul - safrinha. Sete Lagoas: Embrapa Milho e Sorgo, 2004. 12 p. (Embrapa Milho e Sorgo. Circular técnica, 46). 